\title{
Physiological and biochemical traits as tools to screen sensitive and resistant varieties of tomatoes exposed to salt stress
}

\author{
Qazi Fariduddin $^{1 *}$, Bilal Ahmad Mir ${ }^{1}$, Aqil Ahmad ${ }^{1}$ \\ 'Plant Physiology and Biochemistry Section, Department of Botany, Aligarh Muslim University, Aligarh, India. \\ ${ }^{*}$ Corresponding author: qazi_farid@yahoo.com \\ Received: 31 October 2012; Accepted: 21 January 2013
}

\begin{abstract}
The present study was conducted to evaluate salt tolerance in seven different pure-line cultivars of tomato (Solanum Iycopersicum L.) viz. K-21, Pusa Ruby, Pusa Gorav, Hera research, Selection N5, PKM-1 and S-22 based on several physiological and biochemical traits. Seedlings were transplanted to the pots, being exposed to different salinity levels in the form of $\mathrm{NaCl}(0,50,100$, or $150 \mathrm{mM})$ at a 35-day stage of growth for six days. The plants exposed to salt stress presented a significant decline in growth, photosynthetic parameters, maximum quantum yield of PSII and leaf water relations, which were drastically reduced in variety S-22, while variety K-21 was the least affected. Electrolyte leakage was superior in proportion to an increase in salinity levels. Proline content and activity of antioxidant enzymes catalase, peroxidase, and superoxide dismutase were found maximum in variety K-21. Almost all the growth and physiological and biochemical traits had a significant genotypic variation, indicating that these parameters could be used as novel screening criteria for selecting the tolerant and sensitive cultivars exposed to salt stress.
\end{abstract}

Keywords: salt tolerance, Solanum lycopersicum L., physiological and biochemical traits, screening.

\section{INTRODUCTION}

Almost three fourth of the Earth's surface is covered by saline water; therefore, it may not be surprising that salts affect a significant proportion of the world's land surface. Therefore, salt stress poses a real threat to sustainable agriculture, especially in areas where secondary salinization has developed through irrigation, poor drainage, or deforestation. Salt-affected soils fall broadly into two categories: sodic and saline. In sodic soils, sodium chloride constitutes the majority of salts and is dominated by excess sodium on exchange sites and a high concentration of carbonate or bicarbonate anions; they have a high pH (8 to 10) with high sodium absorption ratio (SAR) and poor soil structure. Saline soils are generally dominated by sodium ions, but the dominant is chloride and sulphate anions; $\mathrm{pH}$ values and SARs are much lower and have higher electrical conductivity ( $\left.>4 \mathrm{dS} \mathrm{m}^{-1}\right)$ than the sodic ones (Flowers and Flowers, 2005). Saltaffected soils have enough concentrations of soluble ones to affect the growth of most plant species.

Typically, most of the soil salinity happens due to sodium chloride and therefore plants have evolved specific mechanisms to regulate $\mathrm{NaCl}$ accumulation or exclusion. High salinity causes both hyperionic and hyperosmotic stresses, finally affecting plant growth. Plants are usually classified as glycophytes or halophytes according to their capacity to grow on highly saline soils (Flowers et al., 1977). Halophytes are the natural dwellers 
of highly saline soils and have an efficient mechanism for excluding salts from their roots and leaves, and some can also withstand those more than twice the concentration of seawater. These properties make them the potential candidates for the identification of specific genes for salt-tolerance (Breckle, 2002).

Salinity involves osmotic, ionic (mainly due to $\mathrm{Na}^{+}, \mathrm{Cl}^{-}$, and $\mathrm{SO}_{4}{ }^{2-}$ ), and secondary stresses such as nutritional imbalances and oxidative stress in glycophytes (Zhu, 2002). It also affects plants in different ways like the osmotic effects, specific-ion toxicity, and/or nutritional disorders (Läuchli and Epstein, 1990). In order to manage the damaging effects of salt stress, plants have evolved many biochemical and molecular mechanisms. Some of the biochemical strategies include regulation of ion uptake by roots and their transport into leaves; selective exclusion of salt ions; ion compartmentalization; synthesis of compatible osmolytes for osmotic adjustment; changes in the membrane structure; induction of antioxidative enzymes for neutralization of reactive oxygen species (ROS); and stimulation of phytohormones for growth regulation (Zhu, 2001; Parida and Das, 2005). The extent by which one mechanism affects the plant over the others depends upon many factors including species, genotype, plant stage, composition, and strength of the salinizing solution (Läuchli and Grattan, 2007).

Understanding the genetic, physiological, and biochemical control of these mechanisms is an important step towards the development of crop varieties with improved levels of salt tolerance. Thus, the identification of enzymes or compounds whose expression and/ or production are altered by salt stress can perhaps aid in the development of salt-tolerant cultivars (Shen et al.,1997; Winicov, 1998). Studies with different crop plants like tomato, rice, barley, and citrus indicate that salt tolerance is a quantitative trait involving many genes and relatively a number of environmental factors (Flowers, 2004). Tomato is sensitive to moderate levels of salt stress and is produced in areas that are increasingly affected by salinity (Frary et al., 2010). However, some of the salt-tolerant wild relatives of tomato are easy to cross with cultivated tomato and provide a rich source of resistance and tolerance genes for biotic and abiotic stresses, including salinity (Hajjar and Hodgkin, 2007). The resistant varieties may grow better in the salt-affected areas, since they have developed better avoidance or tolerance strategies against salt stress. Cultivars of various crop plants display marked differences for salt tolerances, such as mustard (Hayat et al., 2011), barley (Belkhodja, 1994), and wheat (Hollington, 1998).
Keeping all these points in mind, the present study was designed with the aims of studying the degree of tolerance among different varieties of Solanum lycopersicum L. under different salt concentrations and of finding out the most sensitive and resistant variety. Moreover, it is expected to provide an opportunity to study the response of different cultivars of Solanum lycopersicum L. towards salinity stress and further to analyse their genetic diversity. The promising lines could be exploited both for direct use in moderately contaminated saline soils or for use in selection and breeding programs in order to make further advancement in salt tolerance.

\section{MATERIAL AND METHODS}

Biological material and growth conditions: The seeds of seven different varieties of Solanum lycopersicum L. (Selection N5, Hera research, K-21, Pusa Ruby, Pusa Gorav, PKM-1, S-22) were obtained from the Department of Horticulture, Indian Agricultural Research Institute, New Delhi, India. Healthy and uniform sized seeds of all varieties were surface sterilized with $1 \%$ sodium hypochlorite solution for ten minutes, followed by repeated washings with double distilled water (DDW). The sterilized seeds were sown in earthen pots to create nursery. At 20 days after sowing (DAS), seedlings were subsequently transplanted to the maintained pots, filled with soil and farmyard manure $(6: 1)$. Irrigation was done by using tap water as and when required.

Treatments and harvest: 35 -day-old seedlings were supplied with $0,50,100$, or $150 \mathrm{mM} \mathrm{NaCl}$ solution for six days in order to develop the required salinity level. Thereafter, plants were irrigated with tap water only when necessary. Each treatment was replicated five times with three plants each time. The plants were allowed to grow, to be assessed at 60 DAS for various growth, photosynthetic, and biochemical parameters. The fully expanded third leaves of each plant were harvested, immediately frozen in liquid nitrogen, and stored at $-80^{\circ} \mathrm{C}$ until required for analysis. The experiment was conducted under completely randomized block design.

Plant growth analysis: The plants were removed from the pots along with the soil and were dipped in a bucket filled with water. They were moved gently to remove the adhering soil particles and the lengths of root and shoot were measured by using a meter scale. Also, they were then placed in an oven run at $60^{\circ} \mathrm{C}$ for 24 hours and weighed to record the plant dry mass. The leaf area 
was manually measured by using a graph sheet, in which the squares covered by the leaf were counted to note the leaf area.

Determination of leaf electrolyte leakage: The total inorganic ions leaked out of the leaves were measured by the method described by Sullivan and Ross (1979). Twenty leaf discs were taken in a boiling test tube, containing $10 \mathrm{~mL}$ of deionized water and electron conductivity (EC) was measured (ECa). The contents were heated at 45 and $55^{\circ} \mathrm{C}$ for 30 minutes each in a water bath, being EC measured (ECb). Later, the controls were boiled at $100^{\circ} \mathrm{C}$ during ten minutes, and EC was again recorded (ECC). The electrolyte leakage (EL) of the leaf was calculated using the formula: $E L(\%)=[(E C b-E C a) /(E C c)] \times 100$.

Determination of chlorophyll content (soil and plant analyzer development value): The SPAD value of chlorophyll in fresh leaf was measured by using the SPAD chlorophyll meter (SPAD-502; Konica, Minolta sensing, Inc., Japan).

Chlorophyll fluorescence i.e. Maximum quantum yield of Photosystem II (Fv/Fm): Chlorophyll fluorescence was measured by using a leaf chamber fluorometer (Li-COR 6400-40, Li-COR, and Lincoln, NE, USA). All measurements were carried out at a photosynthetic photon flux density (PPFD) of $1,500 \mu \mathrm{mol} \mathrm{m}^{-2} \mathrm{~s}^{-1}$ with a constant airflow rate of $500 \mu \mathrm{mol} \mathrm{s}{ }^{-1}$. The minimal fluorescence level $\left(F_{0}\right)$ was determined by modulated light, which was low $\left(<1 \mu \mathrm{mol} \mathrm{m}{ }^{-2} \mathrm{~s}^{-1}\right)$ enough to avoid any significant variable fluorescence, whereas the maximal fluorescence $(\mathrm{Fm})$ was determined by a $0.8 \mathrm{~s}$ saturation pulse at $4,200 \mu \mathrm{mol} \mathrm{m} \mathrm{m}^{-2} \mathrm{~s}^{-1}$ on dark-adapted leaves (30 minutes). The leaf was dark-adapted for 30 minutes prior to measurement of $\mathrm{Fv} / \mathrm{Fm}$.

Leaf water potential: Leaf water potential was measured in fresh and detached leaves of the sample plants by using PSYPRO, a water potential system (WESCOR, Inc. Longman, USA).

Analysis of leaf gas exchange parameters: Gasexchange parameters were determined on the third-fullyexpanded leaves between 11 and 12 hours by using an infrared gas analyzer portable photosynthetic system (Li-COR 6400, Li-COR, and Lincoln, NE, USA). To measure the net photosynthetic rate $\left(\mathrm{P}_{\mathrm{N}}\right)$ and its related attributes (stomatal conductance $-g_{s}$, internal $\mathrm{CO}_{2}$ concentration $-\mathrm{C}_{\mathrm{i}}$, and water use efficiency - WUE), air temperature, relative humidity, $\mathrm{CO}_{2}$ concentration, and PPFD were maintained at $25^{\circ} \mathrm{C}, 85 \%$, $600 \mu \mathrm{mol} \mathrm{mol}^{-1}$, and $800 \mu \mathrm{mol} \mathrm{mol}^{-2} \mathrm{~s}^{-2}$, respectively.
Antioxidative enzymes assay: For the assay of antioxidant enzymes, the leaf tissue $(0.5 \mathrm{~g})$ was homogenized in a $50 \mathrm{mM}$ phosphate buffer $(\mathrm{pH}=7.0)$ containing $1 \%$ polyvinylpyrrolidone. The homogenate was centrifuged at $25,200 g_{n}$ for ten minutes at $4^{\circ} \mathrm{C}$, and the supernatant was used as a source of enzymes catalase, peroxidase, and superoxide dismutase.

For the estimation of peroxidase (E.C. 1.11.1.7) activity (Chance and Maehly, 1956), the enzyme extract $(0.1 \mathrm{~mL})$ was added to the reaction mixture consisting of pyrogallol, phosphate buffer ( $\mathrm{pH}=6.8$ ), and $1 \% \mathrm{H}_{2} \mathrm{O}_{2}$. The change in the absorbance was read at every 20 seconds for two minutes at $420 \mathrm{~nm}$ on a spectrophotometer (ELICO SL171 MINI SPEC). A control set was prepared by adding DDW instead of enzyme extract. The reaction mixture for catalase (E.C. 1.11.1.6) consisted of phosphate buffer $(\mathrm{pH}=6.8), 0.1 \mathrm{M} \mathrm{H}_{2} \mathrm{O}_{2}$, and enzyme extract $(1.0 \mathrm{~mL})$. $\mathrm{H}_{2} \mathrm{SO}_{4}$ was added to the reaction mixture, after its incubation for one minute at $25^{\circ} \mathrm{C}$, and it was titrated against potassium permanganate solution (Chance and Maehly, 1956).

The activity of superoxide dismutase (E.C. 1.15.1.1) was assayed by measuring its ability to inhibit the photochemical reduction of nitroblue tetrazolium using the method of Beauchamp and Fridovich (1971). The reaction mixture included $50 \mathrm{mM}$ phosphate buffer ( $\mathrm{pH}=7.8), 13 \mathrm{mM}$ methionine, $75 \mathrm{mM}$ nitroblue tetrazolium, $2 \mathrm{mM}$ riboflavin, $0.1 \mathrm{mM}$ EDTA, and 0-50 $\mu \mathrm{L}$ enzyme extract and was placed under a 15-W fluorescent lamp. The reaction was started by switching on the light and was allowed to run in a ten-minute period. Fifty per cent inhibition by light was considered as one enzyme unit.

Determination of proline accumulation: The proline content in fresh leaves was determined according to Bates et al. (1973) methods. The substance was extracted in sulfosalicylic acid for which an equal volume of glacial acetic acid and ninhydrin solutions were added. The sample was heated at $100^{\circ} \mathrm{C}$, to which $5 \mathrm{~mL}$ of toluene were added after cooling. The absorbance of the toluene layer was read at $528 \mathrm{~nm}$ on a spectrophotometer.

Determination of nitrate reductase (E.C. 1.6.6.1) and carbonic anhydrase (E.C. 4.2.1.1) activity: The activity of nitrate reductase (NR) was measured following the method laid down by Jaworski (1971). The fresh leaf samples were cut into small pieces and transferred to plastic vials, with phosphate buffer $(\mathrm{pH}=7.5), \mathrm{KNO}_{3}$, and isopropanol was incubated at $30^{\circ} \mathrm{C}$ during two hours. After incubation, sulfanilamide and $\mathrm{N}$-1-naphthylethylenediamine hydrochloride solutions were added. The absorbance was read at $540 \mathrm{~nm}$ on a 
spectrophotometer (Spectronic 20D; Milton Roy, USA). The activity of carbonic anhydrase (CA) in the leaves was measured following the method described by Dwivedi and Randhawa (1974). The leaf samples were cut into small pieces in a cysteine hydrochloride solution. They were blotted and transferred in a test tube, followed by the addition of phosphate buffer ( $\mathrm{pH}=6.8), 0.2 \mathrm{M} \mathrm{NaHCO}_{3}$, bromothymol blue, and methyl red indicator, at the last. Reaction was titrated against $0.5 \mathrm{NHCl}$. The activity of the enzyme was expressed on a fresh mass basis.

Proteinestimation:1.0g freshtissuewashomogenized in chilled protein extraction buffer $(40 \mathrm{mM}$ tris- $\mathrm{HCl}, \mathrm{pH}=7.5$; $0.07 \% \beta$-mercaptoethanol, $2 \%$ polyvinylpyrrolidone, $1 \%$ Triton-X and $1 \mathrm{mM}$ phenylmethane sulfonyl floride (PMFS), $1 \mathrm{mM}$ ethylenediaminetetraacetic acid (EDTA) with the help of mortar and pestle. Homogenate was centrifuged at $20,000 \mathrm{xg}$ for ten minutes, and supernatant was collected for the estimation of protein using Bradford's method (1976).

Statistical analysis: Each treatment was replicated five times. The values for various parameters of the plants were subjected to statistical analysis following the standard procedure described by Gomez and Gomez (1984). The means were compared by the least significant difference (LSD) test in order to study the significance at a $5 \%$ level of probability.

\section{RESULTS}

Growth biomarkers: Plants exposed to salt stress ( 0 , 50,100 , or $150 \mathrm{mM}$ ) showed significant decrease in almost all the growth biomarkers like shoot and root lengths, fresh and dry masses of root and shoot and leaf areas at 60 DAS, in comparison to non-stressed control plants (Figures 1 and 2A). The maximum decrease was noticed with the highest level of salinity, i.e., $150 \mathrm{mM}$, in all varieties. Among the several cultivars, K-21 was the most resistant and showed only a $31.3,30,34.9,34.1$, and $35.2 \%$ decrease in shoot and root lengths, shoot and root fresh masses, and leaf area respectively, at the highest salinity level $(150 \mathrm{mM})$, whereas S-22 was the most sensitive and showed a loss of $43.5,43.1,47.3,49.4$, and $48.2 \%$ respectively. Varietal decrease in the values of growth parameters followed the trend: S-22>PKM-1>Selection N5>Hera research>Pusa Gorav>Pusa Ruby>K-21.

Chlorophyll content and chlorophyll fluorescence: The salinity stress significantly lowered the chlorophyll (Chl) content (Figure 2C), and Fv/Fm in all varieties of tomato in proportion to increasing concentration of the salt (Figure 3A). The maximum decrease in both parameters by salt stress was found in S-22 followed by PKM-1. The highest salinity level $(150 \mathrm{mM})$ proved to be the most toxic for all cultivars and the values were 60.8 and $35.1 \%$ in S-22 and 52.8 and $33.3 \%$ in PKM-1 less compared with the respective controls. However, the minimum loss in both parameters was found in the variety K-21 at all the four levels of salinity.

Photosynthesis and related attributes: A linear decrease in the values of photosynthetic attributes $\left(C_{i}, P_{N}, g_{s}\right.$, and WUE) was found in all varieties in proportion to the level of salinity $(0,50,100$, or $150 \mathrm{mM})$ at $60 \mathrm{DAS}$ (Figures 2B,D-F). The K-21 variety exhibited minimum decrease in the values, compared with the control, in response to the highest level of salinity (i.e., $150 \mathrm{mM}$ ) $\mathrm{P}_{\mathrm{N}}$ by $29.1 \%, g_{s}$ by $54.8 \%$, WUE by $40.1 \%$, and $\mathrm{C}_{i}$ by $39.8 \%$ respectively. Yet, the maximum damage in photosynthetic attributes was found in S-22, at all given salinity levels.

Leaf water potential: The leaf water potential showed a linear decrease as the concentrations of $\mathrm{NaCl}$ were increased (Figure 3B). The leaf water potential values for the varieties K-21, Pusa Ruby, Pusa Gorav, Hera research, Selection N5, PKM-1, and S-22 decreased by 43.8, 49.9, $55.7,59.9,61.7,71.8$, and $78.3 \%$ at $150 \mathrm{mM}$, compared to their respective controls. However, the decrease was significantly lower at 50 and $100 \mathrm{mM}$ salt concentrations.

Electrolyte leakage: The observations depicted in Figure $3 \mathrm{C}$ clearly reveal that $\mathrm{NaCl}$ treatment generated a significant increase in the EL (solute). But the varieties responded differentially to such management $(0,50,100$, or $150 \mathrm{mM}$ ). In all of them, the maximum value for $\mathrm{EL}$ was recorded in plants exposed to $150 \mathrm{mM} \mathrm{NaCl}$. Those severely affected by the stress were S-22, PKM-1, and Selection-N5. They also experienced a significant damage even at the lowest concentration $(50 \mathrm{mM})$ of $\mathrm{NaCl}$, in which the values for EL were 50.1, 46.1, and $42 \%$, being more than the respective controls. Nevertheless, the varieties K-21, Pusa Ruby and Pusa Gorav had maximum resistance to $\mathrm{NaCl}$. Herein, $150 \mathrm{mM}$ of $\mathrm{NaCl}$ increased the EL only by $40.0,42.6$, and $45.6 \%$ over the controls. The pattern of resistance demonstrated by these three cultivars was K-21>Pusa Ruby>Pusa Gorav.

Nitrate reductase and carbonic anhydrase activities: The activities of nitrate reductase and carbonic anhydrase diversified significantly with respect to $\mathrm{NaCl}$ concentration (Figures $4 A, B)$. Out of the different salinity levels $(50,100$, or $150 \mathrm{mM}$ ), the lowest concentration was least toxic. The cultivars PKM-1 and S-22 were highly sensitive, whereas 


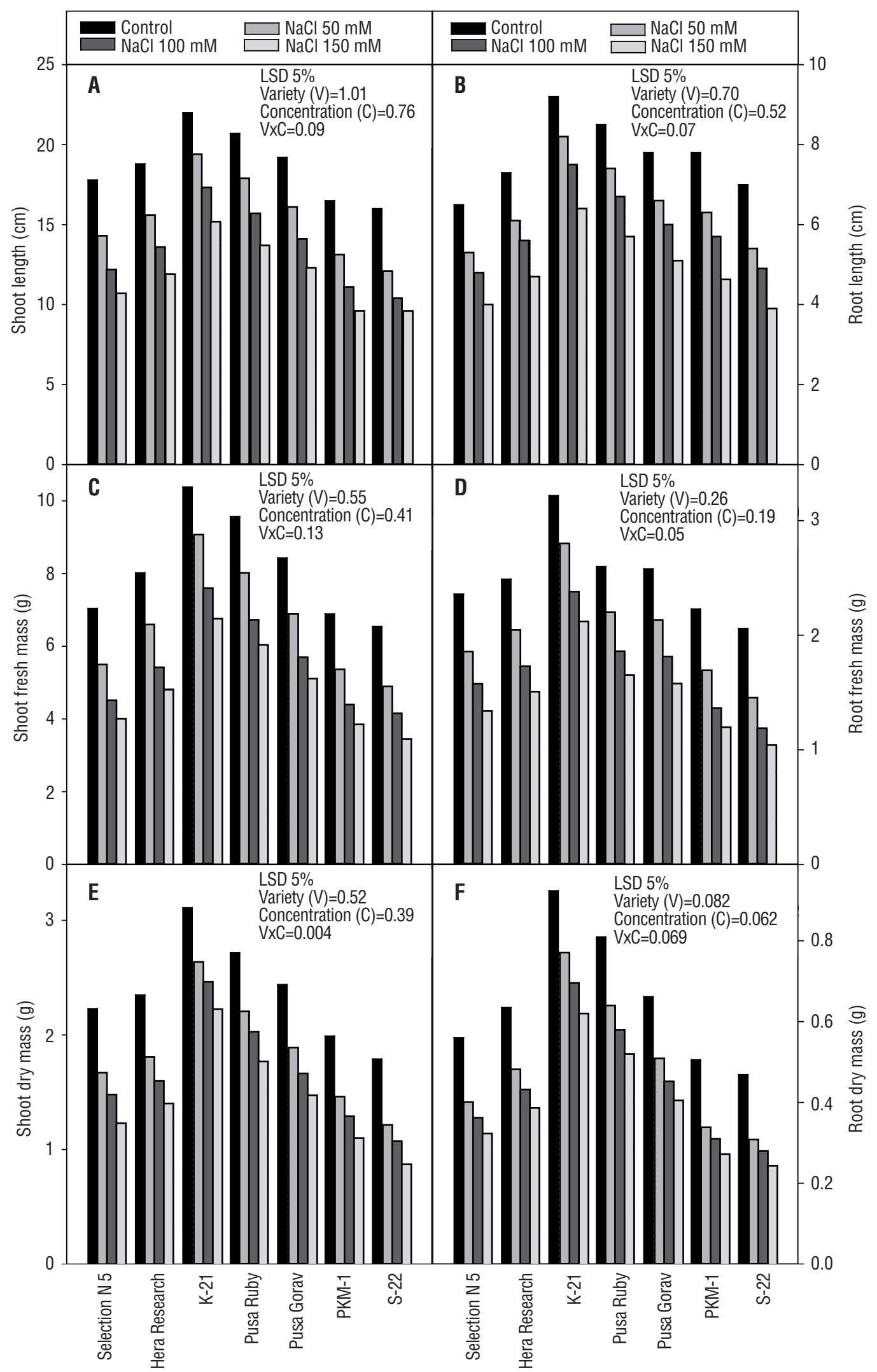

Figure 1. Effect of different levels of salinity ( $\mathrm{NaCl} ; 0,50,100$, or $150 \mathrm{mM}$ ) on the (A) shoot length, (B) root length, (C) shoot fresh mass, (D) root fresh mass, (E) shoot dry mass, and (F) root dry mass in seven varieties of tomato (Solanum lycopersicum L.) at 60 DAS. 


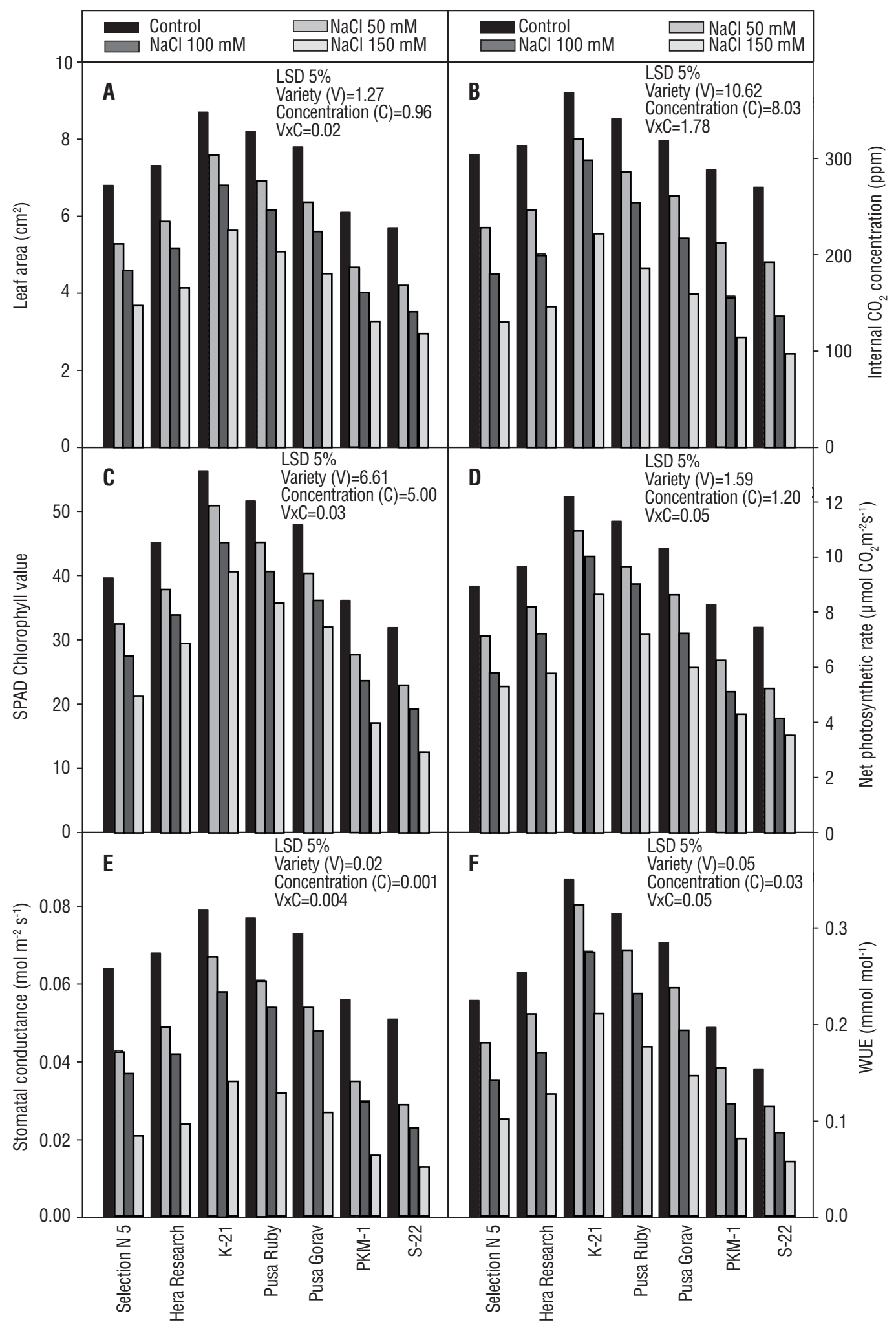

Figure 2. Effect of different levels of salinity ( $\mathrm{NaCl} ; 0,50,100$ or $150 \mathrm{mM}$ ) on the (A) leaf area, (B) internal $\mathrm{CO}_{2}$ concentration, (C) SPAD chlorophyll value, (D) net photosynthetic rate, (E) stomatal conductance and (F) water use efficiency in seven varieties of tomato (Solanum lycopersicum L.) at 60 DAS. 


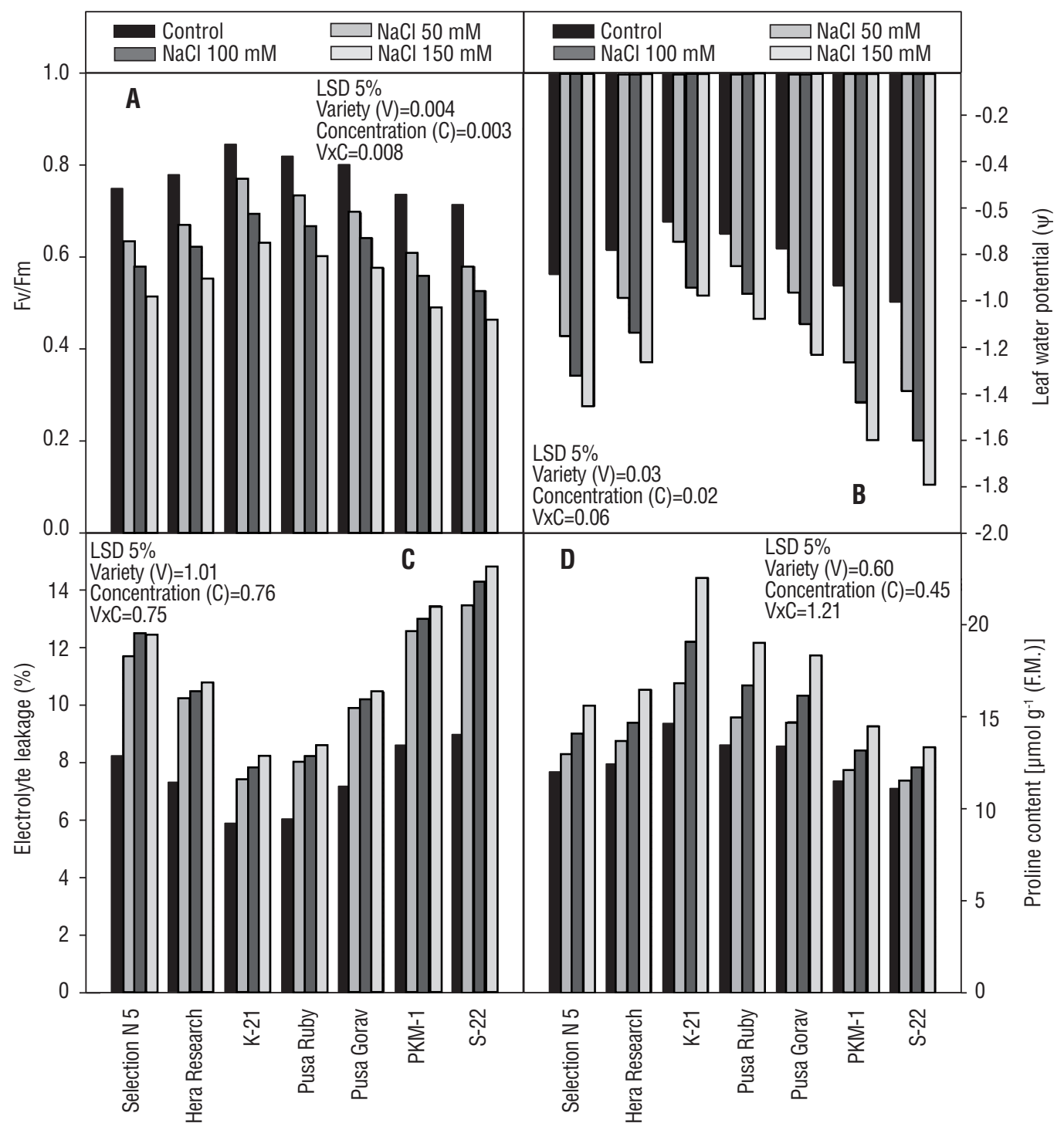

Figure 3. Effect of different levels of salinity ( $\mathrm{NaCl} ; 0,50,100$, or $150 \mathrm{mM}$ ) on the (A) maximum quantum yield ( $\mathrm{Fv} / \mathrm{Fm})$, (B) leaf water potential $(\psi),(C)$ electrolyte leakage, (D) proline content in seven varieties of tomato (Solanum lycopersicum L.) at 60 days after sowing.

$50 \mathrm{mM}$ salinity level reduced the values for NR and CA by 25.3 and $35.2 \%$ in S-22 and 23.9 and $30.1 \%$ in PKM1 , below their respective controls. K-21 was the most resistant to salinity stress. Yet, $150 \mathrm{mM}$ of $\mathrm{NaCl}$ was more toxic and caused a severe loss in the activity of nitrate reductase and carbonic anhydrase, and their respective values were decreased by 50.3 and $54.8 \%$ in cultivar S-22.

Proline content: Proline content in all the cultivars increased with increase in the level of salinity (Figure 3D). Cultivar K-21 possessed maximum values for proline content, compared to the other cultivars, at all the three salinity levels, which were 15,30 and $54.1 \%$ higher, over the control. On the other hand, S-22 possessed the least values at all the salinity levels. The proline content in various cultivars followed the order K-21>Pusa-Ruby> Pusa-Gorav>Hera-Research>Selection-N5>PKM-1> S-22.

Protein content: Protein content of Solanum lycopersicum L. genotypes varied at all the levels of salt $(0,50,100$ or $150 \mathrm{mM})$ treatment (Figure 4F). Protein content significantly decreased with an increase in the level of salinity. Variety S-22 experienced severe damage at all levels of salinity and had $24.1,34.7$ and $42.3 \%$ less protein content in response to 50,100 or $150 \mathrm{mM}$ of $\mathrm{NaCl}$. K-21 was most resistant and showed only $26.8 \%$ 


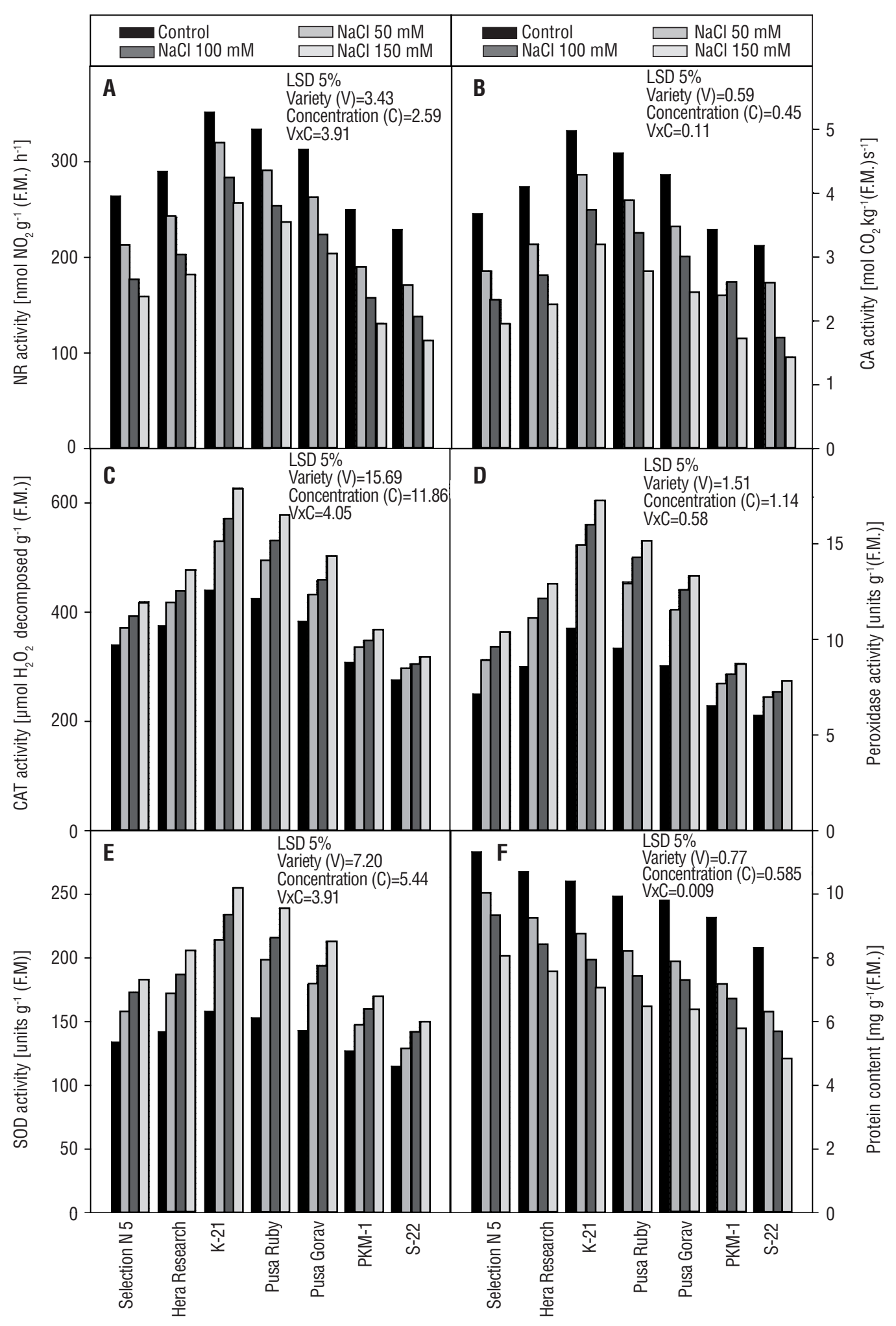

Figure 4. Effect of different levels of salinity ( $\mathrm{NaCl} ; 0,50,100$, and $150 \mathrm{mM}$ ) on the (A) nitrate reductase - NR activity, (B) carbonic anhydrase - CA activity, $(C)$ catalase - CAT activity, (D) peroxidase - POX activity, (E) superoxide dismutase - SOD activity, and (F) protein content in the seven different varieties of tomato (Solanum lycopersicum L.) at 60 days after sowing. 
decrease at $150 \mathrm{mM}$. It was closely followed by PusaRuby which showed a decrease of only $28.8 \%$ at the same salinity level.

Antioxidant enzymes: The activity of antioxidant enzymes, i.e., catalase - CAT, peroxidase - POX, and superoxide dismutase - SOD was significantly superior with the increase in salinity level (Figure 4C-E). The lowest concentration of $\mathrm{NaCl}$ was least toxic, for all genotypes. The varieties Selection-N5, PKM-1 and S-22 were highly sensitive to the salt stress. The higher concentrations (100 and $150 \mathrm{mM}$ ) of $\mathrm{NaCl}$ were extremely toxic for all varieties. Among them, K-21, Pusa-Ruby and Pusa-Gorav showed significantly higher values of CAT, POX, and SOD over the control. The increase generated in CAT, POX, and SOD activities at $150 \mathrm{mM}$ of $\mathrm{NaCl}$ in variety $\mathrm{K}-21$ was 42.5 , 63.3 , and $61.9 \%$, respectively, above the control.

\section{DISCUSSION}

The values for all growth biomarkers (root and shoot lengths; leaf area; fresh and dry masses of plants) decreased significantly in the plants exposed to salt stress. Moreover, the responses of various genotypes differed significantly, with the least reduction observed in variety K-21. With an increase in the level of salt stress, the decrease in all the above growth parameters were also higher. These results are in agreement with those of Yildirim et al. (2006), who showed that salinity caused a marked reduction in growth parameters of squash plants. One cause of growth rate reduction under stress conditions could be inadequate photosynthesis (Figure 2D), less stomatal conductance (Figure 2E), and consequently the limited carbon dioxide uptake (Hayat et al., 2009; Karlidag et al., 2011). Also, stress induced growth loss could be the result of inhibited cell division and expansion and increased H-pumping and apoplastic pH (Pitann et al., 2009). As per the acid-growth theory, lower apoplastic $\mathrm{pH}$ is required for cell growth to activate wallloosening enzymes like expansins (Cosgrove, 2000).

The present investigation revealed that $\mathrm{NaCl}$ stress caused a significant reduction in the chlorophyll content (Figure 2C). This is due to the increased activity of chlorophyll-degrading enzyme, i.e., chlorophyllase, and inhibition of chlorophyll synthesis: 5-aminolevulinic acid (ALA) synthase, under salt stress conditions (Santos, 2004). NaCl also inhibited the activities of the key enzymes of photosynthesis namely Rubisco and PEP carboxylase (Soussi et al., 1998). Furthermore, $\mathrm{NaCl}$ induces the closure of stomata (Wang et al., 2011), therefore it decreases partial $\mathrm{CO}_{2}$ pressure and consequently lowers the intercellular $\mathrm{CO}_{2}$ concentration and finally the activity of carbonic anhydrase (Figure 4B). Presence of excess $\mathrm{Na}^{+}$in the salt-stressed plants causes a membrane injury, which is expressed as EL (Sabra et al., 2012). Besides, salinity (Sudhir and Murthy, 2004) impairs photosynthesis and photosynthetic electron transport chain. All these impaired events finally culminate into a severe loss in the rate of photosynthesis (Figure 2D).

The photosynthetic system is the backbone of plant system, therefore if any changes in these attributes occur due to stress, these parameters could be set as stress markers. In the present study, variability in terms of photosynthetic attributes among the different genotypes of tomato in response to different saline levels was well marked. The performance of genotypes regarding photosynthesis was of the order K-21>Pusa-Ruby>PusaGorav $>$ Hera-Research $>$ Selection-N5>PKM-1>S-22. It is clear that salts damage the photosynthetic machinery at multiple levels, such as pigments biosynthesis (Figure 2C), stomatal functioning and gaseous exchange, structure and function of thylakoid membranes, membrane damage, electron transport, and enzyme activities (Sudhir and Murthy, 2004). This effect can be attributed to the antagonistic influence of $\mathrm{Na}^{+}$to that of $\mathrm{K}^{+}$. $\mathrm{Na}^{+}$indirectly affects the stomatal conductance by reducing the ratio of $\mathrm{K}^{+} / \mathrm{Na}^{+}$(Shahid et al., 2011; Sabra et al., 2012). Stomatal closure as a result of excess salt decreases the partial $\mathrm{CO}_{2}$ pressure (Abbruzzese et al., 2009) as well as the internal $\mathrm{CO}_{2}$ concentration (Figure $2 \mathrm{~B}$ ), and consequently the $\mathrm{CA}$ activity (Figure $4 \mathrm{~B}$ ), for its activity is largely regulated by $\mathrm{CO}_{2}$ concentration (Tiwari et al., 2005). CA is the enzyme that catalyzes the reversible hydration of $\mathrm{CO}_{2}$ and maintains its constant supply to Rubisco (Majeau and Coleman, 1994).

Rubisco is the primary enzyme for carbon fixation, which largely regulates the accumulation of photosynthates and energy metabolism. The reported decrease in the activity of CA by salinity is in agreement with other studies (Hayat et al., 2011). The damage caused by salt stress can also be attributed to the physiological drought generated by $\mathrm{NaCl}$ (Hopkins, 1995) as evident from the decreased WUE (Figure 2F). Likewise, decrease in photosynthetic attributes $\left(P_{N}, g_{s}, C, E\right.$, and WUE) in response to salinity has also been reported in Brassica juncea (Yusuf et al., 2008). Moreover, a linear decrease in the quantum yield of PS II (Figure 3A) was also observed in the genotypes of tomato. The reason behind this could be due to physiological drought generated by the salinity, which may in turn increase the D2 protein turnover of PS II leading to its decrease in quantum yield (Figure 3A). 
A similar inferiority in the quantum yield of PS II was observed by Shahbaz et al. (2008) in Triticum aestivum and by Hayat et al. (2010) in Vigna radiata exposed to salinity.

Overproduction of ROS is a common consequence of different stress factors, including salinity (Hernandez and Almansa, 2002). To maintain metabolic functions under stress conditions, the balance between generation and degradation of ROS is required, otherwise oxidative injuries may occur. Unless controlled, ROS may oxidize and eventually cause damage to proteins, lipids, and nucleic acids. However, some of them can also serve as signalling molecules, if they are produced transiently but not accumulated (Foyer and Noctor, 2005). Their function as signalling molecules or as toxic ROS ultimately depends on the balance between their formation and removal by the antioxidative scavenging systems (Hernandez and Almansa, 2002). Proline acts as a cytosolic osmoticum, scavenger of $\mathrm{OH} \cdot-$ radical and can interact with cellular macromolecules, such as DNA, protein, membranes, and can stabilize their structure and function (Kavi Kishor et al., 2005). Therefore, it was expected that the exposure of tomato plants to $\mathrm{NaCl}$ could higher the level of antioxidant enzymes as well as that of proline in order to overcome the oxidative stress generated by the salinity one. K-21 was found to have a well-developed antioxidant system that dealt with the salinity stress more efficiently than the other varieties. The performance order of several genotypes regarding antioxidant system is K-21>PusaRuby $>$ Pusa-Gorav $>$ Hera-Research $>$ Selection-N5 $>$ $P K M-1>S-22$. Higher activity of antioxidative enzymes in a genotype provided more resistance to salt stress whereas lower activity resulted in a more sensitive genotype (Shalata et al., 2001).

Nitrate reductase (NR) mediates the reduction of nitrate to nitrite, which is regarded as a rate limiting step in plant growth and development (Solmonson and Barber, 1990). Nitrate reductase activity provides a good estimative of the nitrogen status of plants and is related with plant growth and yield (Srivastava, 1980). In the present study, salinity stress decreased activity of nitrate reductase (NR). The reason for its decreased activity (Figure $4 \mathrm{~A}$ ) may be attributed to reduced $\mathrm{NO}_{3}^{-}$uptake by plant roots under salt stress (Tabatabaei, 2006), or to the decreased synthesis of NR protein (Flordeliza et al., 2000), as the total soluble protein was also lowered with the increase in $\mathrm{NaCl}$ concentration (Figure 4F).

The decrease in protein content might be due to the increased activity of proteases (Parida et al., 2004). The level of free amino acid proline increased due to salt stress, triggering an increase in total amino acid pool by decreasing protein content, which reflects the mode of adjustment to salinity stress. These results suggest that decreased protein content in tomato plants might be due to increased activity of both acid and alkaline proteases (Parida et al., 2004). Protein hydrolysis by proteases release amino acids which provide osmotic adjustment during $\mathrm{NaCl}$ stress.

General growth, physiological and biochemical traits may be used as effective approaches to screen the tolerant and sensitive varieties of tomato exposed to salt stress. Amongst the selected cultivars of tomato (K-21, Pusa Ruby, Pusa Gorav, Hera research, selection N5, PKM-1, and S-22), K-21 was the most tolerant and S-22 was the most sensitive variety to salt stress. Consequently, we suggest the adoption of K-21 cultivar in the most affected areas by salinity.

\section{ACKNOWLEDGMENTS}

The authors are thankful to University Grants Commission New Delhi, India, for providing funds to this work - Project 39-437/2010 (SR).

\section{REFERENCES}

Abbruzzese G, Beritognolo I, Muleob R, Piazzaia M, Sabattia M, Mugnozza GS, Kuzminsky E (2009) Leaf morphological plasticity and stomatal conductance in three Populus alba L. genotypes subjected to salt stress. Environ. Exp. Bot. 66:381-388.

Bates LS, Waldren RP, Teare ID (1973) Rapid determination of free proline for water stress studies. Plant Soil 29:205-207.

Beauchamp C0, Fridovich I (1971) Superoxide dismutase: improved assays and assay applicable to acrylamide gels. Anal. Biochem. 44:276-287.

Belkhodja R, Morales F, Abadila A, Gomez-Aparisi J, Abadia J (1994) Chlorophyll fluorescence as a possible tool for salinity tolerance screening in barley (Hordeum vulgare L.). Plant Physiol. 138:92-96.

Bradford MM (1976) A rapid and sensitive for the quantitation of microgram quantities of protein utilizing the principle of protein-dye binding. Anal. Biochem. 72:248-254.

Breckle SW (2002) Salinity, halophytes and salt-affected natural ecosystems. In: Läuchli A, Lüttge U (eds), Salinity: EnvironmentsPlants-Molecules, pp. 53-77. Kluwer Academic Publishers, Dordrecht, The Netherlands.

Chance B, Maehly AC (1956) Assay of catalase and peroxidase. Methods Enzymol. 2:764-775.

Cosgrove DJ (2000) Expansive growth of plant cell walls. Plant Physiol. Biochem. 38:109-124. 

TOMATO EXPOSED TO SALT STRESS

Dwivedi RS, Randhawa NS (1974) Evolution of a rapid test of the hidden hunger of zinc in plants. Plant Soil 40:445-451.

Flordeliza FC, Roberta GN, Agtarab ML, Tecson-Mendoza EM, Lips SH (2000) Salt tolerance in corn: growth responses, ion accumulation, nitrate reductase and PEP-carboxylase activities. Philipp J. Crop Sci. 25:17-26.

Flowers TJ (2004) Improving crop salt tolerance. J. Exp. Bot. 55:307-319.

Flowers TJ, Flowers SA (2005) Why does salinity pose such a difficult problem for plant breeders? Agric. Water Manag. 78:15-24.

Flowers TJ, Troke P, Yeo A (1977) The mechanisms of salt tolerance in halophytes. Annu. Rev. Plant Physiol. 28:89-121.

Foyer CH, Noctor G (2005) Redox homeostasis and antioxidant signalling: a metabolic link between stress perception and physiological responses. Plant Cell 17:1866-1875.

Frary A, Göl D, Keles D, Ökmen B, Pinar H, Sigva HÖ, Yemenicioglu A, Doganlar S (2010) Salt tolerance in Solanum pennellii: antioxidant response and related QTL. BMC Plant Biol. 10:58.

Gomez KA, Gomez AA (1984) Statistical Procedures in Agricultural Research. 2nd ed. John Wiley \& Sons, New York, USA.

Hajjar R, Hodgkin T (2007) The use of wild relatives in crop improvement: a survey of developments over the last 20 years. Euphytica 156:1-13.

Hayat S, Masood A, Yusuf M, Fariduddin Q, Aqil A (2009) Growth of Indian mustard (Brassica juncea L.) in response to salicylic acid under high-temperature stress. Braz. J. Plant Physiol. 21:187-195.

Hayat S, Hasan SA, Yusuf M, Hayat Q, Ahmad A (2010) Effect of 28-homobrassinolide on photosynthesis, fluorescence and antioxidant system in the presence or absence of salinity and temperature in Vigna radiata. Environ. Exp. Bot. 69:105-112.

Hayat S, Mir BA, Wani SA, Hasan SA, Irfan M, Ahmad A (2011) Screening of salt-tolerant genotypes of Brassica juncea based on photosynthetic attributes. J. Plant Interact. 6:53-60.

Hernandez JA, Almansa MS (2002) Short-term effects of salt stress on antioxidant systems and leaf water relations of pea leaves. Physiol. Plant. 115:251-257.

Hollington PA (1998) Technological breakthroughs in screening/breeding wheat varieties for salt tolerance. In: National Conference on "Salinity management in agriculture”, CSSRI Karnal, India, 2-5 December 1998.

Hopkins WG (1995) Introduction to plant physiology. John Wiley, New York.

Jaworski EG (1971) Nitrate reductase assay in intact plant tissues. Biochem. Biophys. Res. Co. 43:1274-1279.

Karlidag H, Yildirim E, Turan M (2011) Role of 24-epibrassinolide in mitigating the adverse effects of salt stress on stomatal conductance, membrane permeability, and leaf water content, ionic composition in salt stressed strawberry (Fragaria $\times$ ananassa). Sci. Hortic. 130:133-140.

Kavi Kishor PB, Sangam S, Amrutha RN, Sri Laxmi P, Naidu KR, Rao KRSS, Rao S, Reddy KJ, Theriappan P, Sreenivasulu N (2005) Regulation of proline biosynthesis, degradation, uptake and transport in higher plants: its implications in plant growth and abiotic stress tolerance. Curr. Sci. 88:424-438.

Läuchli A, Epstein E (1990) Plant responses to saline and sodic conditions. In: Tanji KK (ed), Agricultural salinity assessment and management, pp. 113-137. ASCE, New York.
Läuchli A, Grattan SR (2007) Plant growth and development under salinity stress. In: Jenks MA, Hasegawa PM, Mohan SJ (eds), Advances in molecular breeding toward drought and salt tolerant crops, pp. 1-32. Springer, New York.

Majeau N, Coleman JR (1994) Correlation of carbonic anhydrase and ribulose-1,5-bisphosphate carboxylase/oxygenase expression in pea. Plant Physiol. 104:1393-1399.

Parida A, Das AB, Prasanna M (2004) Investigations on the antioxidative defence responses to $\mathrm{NaCl}$ stress in a mangrove, Bruguiera parviflora: differential regulations of isoforms of some antioxidative enzymes. Plant Growth Regul. 42:213-226.

Parida AK, Das AB (2005) Salt tolerance and salinity effects on plants: a review. Ecotox. Environ. Saf. 60:324-349.

Pitann B, Kranz T, Muhling KH (2009) The apoplastic pH and its significance in adaptation to salinity in maize (Zeas mays): comparison of fluorescence microscopy and pH-sensitive microelectrodes. Plant Sci. 176:497-504.

Sabra A, Daayf F, Renault S (2012) Differential physiological and biochemical responses of three Echinacea species to salinity stress. Sci. Hortic. 135:23-31.

Santos CV (2004) Regulation of chlorophyll biosynthesis and degradation by salt stress in sunflower leaves. Sci. Hortic. 103:93-99.

Shahbaz M, Ashraf M, Athar HR (2008) Does exogenous application of 24-epibrassinolide ameliorate salt induced growth inhibition in wheat (Triticum aestivum L.)? Plant Growth Regul. 55:51-64.

Shahid MA, Pervez MA, Balal RM, Mattson NS, Rashid A, Ahmad R, Ayyub CM, Abbas T (2011) Brassinosteroid (24-epibrassinolide) enhances growth and alleviates the deleterious effects induced by salt stress in pea (Pisum sativum L.). Aust. J. Crop Sci. 5:500-510.

Shalata A, Mittova V, Volokita M, Guy M, Tal M (2001) Response of the cultivated tomato and its wild salt-tolerant relative Lycopersicon pennellii to salt dependent oxidative stress: the root antioxidative system. Physiol. Plant. 112:487-494.

Shen B, Jensen RG, Bohnert HJ (1997) Increased resistance to oxidative stress in transgenic plants by targeting mannitol biosynthesis to chloroplasts. Plant Physiol. 113:1177-1183.

Solomonson LP, Barber MJ (1990) Assimilatory Nitrate Reductase: Functional Properties and Regulation. Annu. Rev. Plant Physiol. Plant Mol. Biol. 41:225-253.

Soussi M, Ocana A, Lluch C (1998) Effects of salt stress on growth, photosynthesis and nitrogen fixation in chickpea (Cicer arietinum L.). J. Exp. Bot. 49:1329-1337.

Srivastava HS (1980) Regulation of nitrate reductase activity in higher plants. Phytochemistry 19:725-733.

Sudhir P, Murthy SDS (2004) Effects of salt stress on basic processes of photosynthesis. Photosynthetica 42:481-486.

Sullivan CY, Ross WM (1979) Selecting the drought and heat resistance in grain sorghum. In: Mussel H, Staples RC (eds), Stress Physiology in Crop Plants, pp. 263-328. John Wiley \& Sons, New York.

Tabatabaei SJ (2006) Effects of salinity and $\mathrm{N}$ on the growth, photosynthesis and N status of olive (Olea europaea L.) trees. Sci. Hortic. 108:432-438.

Tiwari A, Kumar P, Singh S, Ansari SA (2005) Carbonic anhydrase in relation to higher plants. Photosynthetica 43:1-9. 
Wang X, Geng S, Ri YJ, Cao D, Liu J, Shi D, Yang C (2011) Physiological responses and adaptive strategies of tomato plants to salt and alkali stresses. Sci. Hortic. 130:248-255.

Winicov I (1998) New molecular approaches to improving salt tolerance in crop plants. Ann. Bot. 82:703-710.

Yildirim E, Taylor AG, Spittler TD (2006) Ameliorative effects of biological treatments on growth of squash plants under salt stress. Sci. Hortic. 111:1-6.
Yusuf M, Hasan SA, Ali B, Hayat S, Fariduddin Q, Ahmad A (2008) Effect of salicylic acid on salinity-induced changes in Brassica juncea. J. Integr. Plant Biol. 50:1-7.

Zhu JK (2001) Plant salt tolerance. Trends Plant Sci. 6:66-71.

Zhu JK (2002) Salt and drought stress signal transduction in plants. Annu. Rev. Plant Biol. 53:247-273. 